\title{
As LINGUAGENS ARTÍSTICAS NA ESCOLA: ALTERNATIVAS PARA UM TRABALHO INTEGRADO
}

\author{
Denise Álvares Campos* \\ Wanderley Alves dos Santos ${ }^{* *}$ \\ Mara Veloso ${ }^{* * *}$
}

\section{Resumo}

Este artigo apresenta uma experiência em ensino integrado de artes no Centro de Ensino e Pesquisa Aplicada à Educação. Através da referida experiência, surgem reflexôes e sugestões sobre esse tipo de prática de ensino.

Palavras-chaVE: ensino de arte, educação interdisciplinar.

\section{The artistic languages in school: alternatives to an integrated work}

\section{Abstract}

This article presents an experience upon integrated art teaching in Centro de Ensino e Pesquisa Aplicada à Educação. Through the mentioned experience, some reflections and suggestions about this kind of teaching practice emerge.

KEY WORDS: Art education, interdisciplinary education.

\section{INTRODUÇÃo}

A legislação brasileira, a partir de 1971 com a lei 5692, propóe a obrigatoriedade do ensino de arte na escola de $1^{\circ}$ grau e alguns cursos de $2^{\circ}$ grau, porém, antes disso, "[...] o ensino das artes havia sido introduzido legalmente no currículo escolar da educação básica com a LDB de 1961 (lei 4024/61), de forma náo obrigatória" (Japiassu, 2001, p. 49).

Considerando a obrigatoriedade imposta em 1971, precisamos destacar que não havia, entretanto, formação específica para arte-educadores na data de promulgação da lei. Conforme Barbosa (1984, p. 16), "somente em 1973 foram criados pelo governo federal os cursos universitários para forma-

\footnotetext{
Doutora em Educação Musical, mestre em Educação, professora do mestrado em música da EMAC/UFG. E-mail: camposilva@cultura.com.br.

** Especialista em Arteterapia na Educação Especial, licenciado em artes plásticas. E-mail: educadorartistico@yahoo.com.br.

*** Professora de dança e teatro, especialista em filosofia da arte. E-mail: maravelloso@ hotmail.com
} 


\section{Revista Solta a Voz, v. 19, n. 2}

ção dos arte-educadores (Licenciatura em Educação Artística)". O ensino de Arte baseava-se, segundo a autora, na prática de ateliê e a parte teórica estava focalizada na história da arte e no estudo do folclore. A formação do arteeducador, por sua vez, estava configurada para uma polivalência dentro da proposta estabelecida, o que é motivo de críticas como a que segue:

Estamos diante de uma deturpação do princípio de interdisciplinaridade, batizado entre nós de polivalência, uma colagem amorfa entre diferentes sistemas semióticos. Esta abordagem projeta no professor-estudante um conceito equivocado de arte, ligada à idéia de nonsense ou totalidade superficial - uma espécie de grande torta de vegetais e frutas mal misturados e assados cuja receita transmite a seus alunos. (Barbosa, 1984, p. 17)

Atualmente, a lei 9394/96 afirma, em seu art. 26, parágrafo 2º que "O ensino da arte constituirá componente curricular obrigatório nos diversos níveis da educação básica, de forma a promover o desenvolvimento cultural dos alunos". A legislação mantém o caráter obrigatório do ensino de arte, ainda que não defina exatamente quais linguagens artísticas compóem tal "ensino de arte". Somente nos PCNs encontramos um tratamento específico das formas de expressão artística, denotando uma ação arte-educacional através de linguagens específicas. $\mathrm{Na}$ prática, o que se constata é que cada instituição educacional atende aos requisitos da lei dentro de suas "possibilidades operacionais", oferecendo uma ou outra das linguagens artísticas.

No Centro de Ensino e Pesquisa Aplicada à Educação da Universidade Federal de Goiás (Cepae/UFG) o ensino de Arte vem ocorrendo há muito tempo, antes mesmo da obrigatoriedade proposta pela legislação. O quadro docente é composto por professores de diferentes linguagens artísticas (artes visuais, música e teatro), que se alternam em todas as séries da educação básica. A proposta de ensino em cada linguagem artística vem sendo construída ao longo do tempo a partir de estudos e qualificação profissional e da experiência direta com o aluno em sala de aula.

Temos transformado as atividades de Arte que realizamos na escola em projetos de pesquisa e extensão, além de tomá-las com objeto de reflexão em artigos, palestras etc.

No momento atual sentimos a necessidade de desenvolver estudos sobre as possibilidades de integração entre as diversas linguagens artísticas. Nosso propósito é o de que todo embasamento conseguido de forma indi- 
vidual por cada professor, de cada linguagem artística, seja compartilhado com o grupo, que se propôs a desenvolver um projeto de pesquisa pautado em uma atuação interdisciplinar.

\section{Pressupostos teóricos}

Os fundamentos teóricos para o Ensino de Arte no Cepae estão dentro da concepção sugerida pelos PCNs. Nessa vertente, existe uma forte acentuação na história da Arte, na apreciação, na análise e na produção artística, também denominada de Arts PROPEL (produção, percepção e reflexão em Arte). Essa abordagem é decorrente dos estudos realizados pelos pesquisadores do Getty Center of Education in Arts.

Juntam-se a isso os trabalhos e estudos desenvolvidos, sobre este tema, por Ana Mae Barbosa, cuja proposta é denominada de triangular, que integra, de forma mais coesa, o fazer artístico, a história da arte, a apreciação e análise da obra artística. Essa proposta, assim o entendemos, nos leva a avançar, de forma segura, para uma ação de excelência no ensino de arte.

A busca pela integração de linguagens artísticas, tema da pesquisa que ora desenvolvemos, tem seus fundamentos nos muitos estudos, discussóes e artigos que têm sido divulgados sobre a interdisciplinaridade no contexto educacional como um todo. A razão do interesse dos educadores por este tema decorre de que "[o] enfoque interdisciplinar consiste num esforço de busca da visão global da realidade, como superação das impressóes estáticas, e do hábito de pensar fragmentador e simplificador da realidade" (Lück, 1994, p. 72).

Mas, antes de avançarmos em busca de uma integração entre diferentes áreas de conhecimento, vemos que nem mesmo na nossa própria área temos conseguido tal integração. Murray Schafer (1991), músico e educador canadense, preocupa-se com esta fragmentação da experiência artística, a qual ele chama de 'fragmentação do sensorium'. Para ele,

[...] uma total e prolongada separação dos sentidos resulta em fragmentação da experiência. [...] Em um determinado momento, poderíamos ainda isolar as artes individuais como estudos separados, mas tendo sempre em mente que fazemos isso com o propósito de desenvolver acuidades sensoriais específicas. Este seria o período central de estudos. Finalmente, havendo já limpado cada uma das lentes da percepção, voltaríamos a uma reconfiguração de todas as formas de arte, dentro da obra de arte total - uma situação na qual "arte" e "vida" seriam sinônimos. (Schafer, 1991, p. 291) 


\section{Revista Solta a Voz, v. 19, n. 2}

A pesquisa se justifica, portanto, por essa necessidade de buscar caminhos para experiências com a Arte de forma não-fragmentada, pela construção paulatina de um currículo integrado entre as diversas linguagens artísticas, que poderá beneficiar aos alunos em sua experiência com a Arte na escola. Temos consciência das dificuldades que uma ação interdisciplinar impóe. Essa dificuldade é reforçada por Barbosa (1984, p. 88) quando diz: "[n]ão se faz interdisciplinaridade com conversas de corredor. É um processo que demanda tempo, estudo conjunto, discussão, análise e síntese". Afirma, ainda, que esse trabalho interdisciplinar não ocorre, necessariamente, com a presença dos professores "[...] numa mesma classe, ao mesmo tempo. A classe pode ter um professor de cada vez, mas todos esses professores devem ter uma comunalidade a explorar dentro de uma proposta e constantemente se encontrarem para rever o trabalho que está sendo feito" (Barbosa, 1984, p. 88).

Os caminhos, ou a metodologia, portanto, para um trabalho conjunto entre as linguagens artísticas podem ser percorridos de diversas maneiras. Citamos, a princípio, a experiência da polivalência, na qual um único professor trabalha todas as linguagens artísticas. Tal experiência apresenta-se inadequada, porque resulta em um "[...] ensino inócuo, uma educação estética descartável, um fazer artístico pouco sólido [...]” (Barbosa, 1984, p. 88). A interdisciplinaridade que buscamos estaria mais próxima de uma "integração alocêntrica", que

[...] é a exploração dos princípios organizadores e da gramática articuladora da obra de arte na música, na expressáo corporal, nas artes visuais e no teatro separadamente, levando entretanto o aluno a perceber o que há de similar e de diferente entre as linguagens artísticas. (Barbosa, 1984, p. 88)

Buscamos, através desse projeto de pesquisa, responder algumas perguntas, tais como: que formas de integração entre as diversas linguagens artísticas são possíveis de se desenvolver na escola? Como efetivar experiências com este propósito? Quais os resultados concretos que tais experiências trazem para o processo de ensino de Arte na escola?

\section{Atividades Desenvolvidas}

As atividades previstas no projeto de pesquisa vêm se desenvolvendo desde 2006, com término previsto para 2009. São propostas anuais, como abordagens diferenciadas das quais falaremos a seguir, com maior detalhamento na proposta desenvolvida em 2006. 


\section{Tema gerador: a ditadura militar (2006)}

O grupo de professores de ensino de Arte atuou, em 2006, nas $8^{\text {as }}$ séries da $2^{a}$ Fase do Ensino Fundamental do Cepae, utilizando horário normal de aulas, na disciplina da grade curricular denominada educação artística. $\mathrm{O}$ tema gerador comum foi o período da ditadura militar no Brasil.

As atividades desenvolvidas partiram de uma contextualização histórica dos principais aspectos do período histórico escolhido. Depois, foram realizadas diversas atividades nas linguagens artísticas específicas, ocupando cada linguagem um bimestre do ano letivo. Em Artes Visuais foram desenvolvidas as seguintes atividades: arte e sociedade, resistência cultural na ditadura; a obra de Diego Rivera e Cândido Portinari; visita a uma galeria de arte; criação artística (colagens, cartazes, charges).

Para as colagens, foram utilizadas técnicas de colagem criativa, a partir de reprodução de obras dos artistas citados.

Outro ponto importante foi a análise da obra de arte, através de exposição de reproduçóes e dinâmica de grupo de estudo das referidas reproduçóes.

Houve, também, criação de textos poéticos; leitura e ilustração de poesias, seguidas de vivências de expressão corporal a partir dos temas de artes visuais, como, por exemplo, diálogos entre artistas do período, tendo em vista a luta pela liberdade de expressão, criados pelos alunos, que pesquisaram, também, imagens digitais que foram usadas no contexto das apresentaçóes (figura 1).

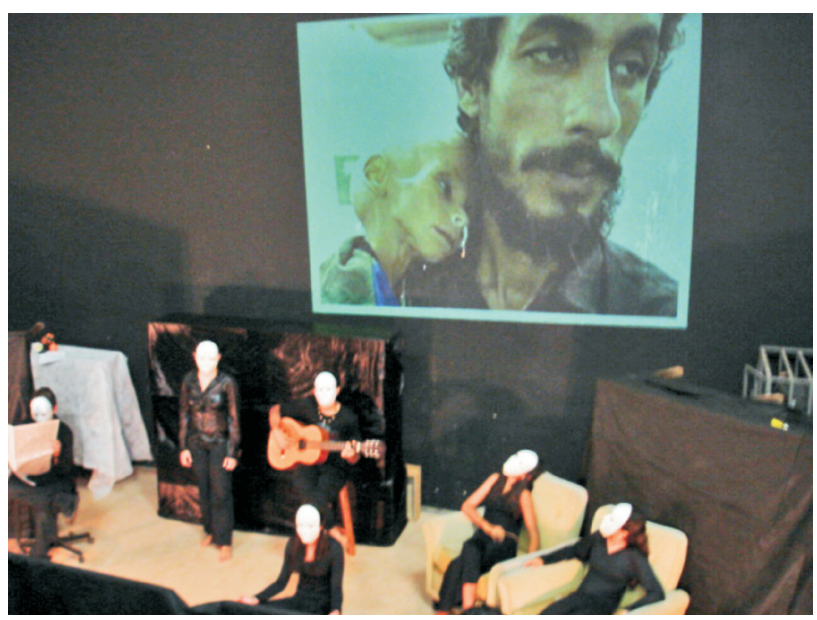

Figura 1 - apresentação dos alunos. 
Os alunos participaram de todas as atividades de forma satisfatória. Foi priorizada a atividade em grupo, estimulando a capacidade de criação e organização. Como atividade extra-classe, fizeram uma visita a uma galeria de arte. Tal atividade favoreceu ao projeto, não só pelo privilégio que os alunos tiveram de conhecer uma galeria de arte, mas, também, por poderem analisar, a partir de produção contemporânea de artes visuais, as questôes da liberdade de expressão e comparar com as dificuldades vividas na época da ditadura militar.

Em música, as atividades desenvolvidas foram: "canção de protesto" (contexto histórico, textos, apreciação de exemplos musicais); criação, em grupos, de uma "canção de protesto" (elaboração da letra, junção letra/ música, ensaio e apresentação da canção); revisão do conteúdo básico de leitura e escrita musical para possibilitar a leitura de partituras de "Cançôes de protesto" e execução/interpretação através do canto ou dos teclados.

Foram feitas gravaçóes das apresentaçóes de alguns grupos. Colocamos, a seguir, a letra de um das cançóes elaboradas pelos alunos:

[1]

Só vejo corrupção, só vejo gente enrolada,

$\mathrm{O}$ tal do mensaláo e as mentiras descaradas.

É tanta informação chegando manipulada,

É tanta embromação, parece até piada.

Não acredito em anúncio, não acredito em TV;

Não acredito em mim, vou acreditar em você?

Não acredito na elite, porque eu não sou otário,

Mas não acredito em alguém só porque foi operário.

Os impostos estão altos

Eu já não compro mais nada

$\mathrm{O}$ meu dinheiro suado

Já não vale nada.

Só vejo pobreza e desigualdade

E tanto partido e nenhum faz nada

Cansei dessa vida que náo se ganha nada

Queremos mudar, revolucionar

Queremos mudança já!

Em teatro as atividades desenvolvidas foram: produção cultural na década de 60; criação de um roteiro a partir de uma situação cotidiana de 
conflitos de idéia e encenação do roteiro criado. Além dessas atividades foi utilizada a peça "A revolução na América do Sul" (Augusto Boal), em momentos que contemplaram a montagem e encenação de uma cena escolhida, além da pesquisa sobre o Teatro do Oprimido, de Augusto Boal.

Depois de realizar atividades em cada uma das linguagens artísticas, os alunos e os professores/pesquisadores se reuniram para pensar sobre uma produção final, na qual as três linguagens artísticas estivessem representadas. A turma dividiu-se em grupos e cada grupo fez sua própria proposta. A elaboração da proposta foi discutida com a equipe de professores, os quais estiveram à disposição, também, nos momentos de ensaio, quando havia dúvidas na utilização de uma ou outra linguagem artística. Foi interessante observar o desenvolvimento do trabalho nos grupos, pois foi o entrosamento entre os membros, a flexibilidade na troca de idéias, a objetividade ao fazer escolhas e o respeito mútuo que ditaram o resultado final que cada grupo apresentou.

As apresentaçóes feitas foram filmadas e tiveram os mais variados formatos, como, por exemplo:

- Utilização do texto da música "Pra não dizer que não falei de flores", com interposição de falas pelos elementos do grupo e utilização de imagens que atualizavam os temas apresentados na canção;

- Utilização de cenas avulsas da peça trabalhada nas aulas de teatro, complementadas pelo canto de cançóes e cenografia;

- Montagem de uma cena composta por uma roda de amigos que reviviam o período da ditadura, falando dos acontecimentos e cantando cançôes da época.

Ao analisar os resultados dessas atividades realizadas em 2006, o grupo de professores percebeu que o tema gerador escolhido ofereceu aos alunos a oportunidade de avaliar a importância da liberdade de expressão. Liberdade de expressão conquistada que se deve valorizar e utilizar com responsabilidade.

Ao artista cabe essa capacidade de mobilizar as multidóes através de sua produção. Neste sentido os alunos de $8^{a}$ série do Cepae foram levados a conhecer e refletir sobre essa dimensão da capacidade do indivíduo de produzir significados e ser sujeito ativo de mudanças, especialmente dentro do período estudado. 


\section{Revista Solta a Voz, v. 19, n. 2}

\section{História da Arte: estudando a música, pintura e teatro barroco (2007)}

Essa proposta, efetivada no ano letivo de 2007, configurou-se como um estudo interdisciplinar teórico-prático de um período da História da Arte, o Barroco. As atividades pedagógicas se desenvolveram como disciplina acessória ${ }^{1}$ que foi oferecida no $1^{\circ}$ semestre de 2007 para os alunos do Ensino Médio do Cepae. Tal disciplina teve como foco uma abordagem abrangente da música, artes visuais e artes cênicas do período barroco, estudando a forma de composição musical, pictórica e cênica.

A carga horária foi dividida entre os professores das três linguagens artísticas (artes visuais, música e teatro) para que cada um apresentasse os conteúdos específicos de sua linguagem artística relacionados ao período histórico abordado.

No entanto, apesar dessa divisão, houve uma previsão de momentos nos quais os três professores estariam juntos, em sala de aula, para: apresentação da disciplina e do projeto de pesquisa; estímulo à elaboração de propostas para um trabalho final onde as linguagens artísticas fossem desenvolvidas de forma integrada; ensaios; apresentação; avaliação final.

Dentre as atividades desenvolvidas podemos listar: apreciação artística dirigida (análise de imagens, apreciação de peças musicais e teatrais); estudo de biografias de artistas; estudo dirigido com textos de história da arte; análise dos estilos de composiçâo visual, musical e cênica; estudo das características gerais da música, teatro e artes visuais do período. O fazer artístico ocorreu através da representação de peças teatrais, canto e execução instrumental de peças barrocas; produção de obras plásticas com argila,

1 De acordo com a nova proposta curricular do ensino Médio em vigor no Cepae, os alunos compóem seu próprio currículo ao elegerem as disciplinas acessórias que desejam cursar, além do Núcleo Básico, que é obrigatório para todos e funciona no turno matutino. "No turno vespertino, os alunos cursam o Núcleo Flexível do currículo: no início do primeiro ano, optam por uma das Áreas de Conhecimento - Biológicas, Exatas ou Humanas - e, entre as disciplinas ofertadas pelas Subáreas que compóem a Área escolhida, selecionam anualmente as 'disciplinas obrigatórias' que desejam cursar. Além disso, dentro o conjunto das disciplinas ofertadas anualmente no Núcleo Flexível, os alunos escolhem as 'disciplinas acessórias optativas' que querem cursar para complementar seu currículo” (Delgado et al., 2007). 
pintura, desenho artístico e multimídia. Ao final, os alunos elaboraram e apresentaram uma produção onde estiveram presentes as três linguagens que compunham a proposta da disciplina.

No decorrer da realização dessas atividades, no entanto, algumas questóes foram se evidenciando e cada professor participante da pesquisa pode percebê-las a seu modo, tanto nos momentos em que atuou com sua linguagem específica quanto nos momentos de atuação conjunta. Essas "percepçóes individuais" foram expostas nas reunióes da equipe que tinham como objetivo discutir as ações que foram sendo executadas, planejar ou replanejar as açóes seguintes e avaliar o resultado final. Ressaltamos, aqui, alguns aspectos citados a título de uma avaliação geral das atividades:

- A regência de sala deve ser objeto de grande atenção, principalmente no momento em que os professores atuam juntos na sala. Os alunos começam a ter que se dirigir a três professores ao mesmo tempo, em algumas questóes de ordem básica, como a autorização para sair de sala, manusear materiais e equipamentos. Para não haver conflito de autoridade entre os educadores há que se definir junto à turma o novo tipo de condução de sala que está em andamento;

- Outro aspecto importante para a participação conjunta dos professores de Arte nas aulas é a questão do horário de aulas da escola. É necessário que ele seja elaborado de forma que possibilite que todos os professores envolvidos na pesquisa possam estar presentes em sala de aula no momento final do projeto;

- Os aspectos metodológicos devem ser observados com rigor. No caso do projeto desenvolvido no Cepae a proposta triangular de Ana Mae Barbosa foi evidenciada. Nesta proposta os componentes do eixo história de arte - análise da obra de arte - fazer artístico são trabalhados de forma equilibrada;

- Tudo indica que a abordagem integrada do ensino de Arte fortalece o entrosamento entre os professores dessa área de ensino e favorece o desenvolvimento dos alunos em um trabalho que integra na prática e na teoria as linguagens artísticas, as quais, na vida social contemporânea, se apresentam de forma integrada, através das novas tecnologias midiáticas. 


\section{Revista Solta a Voz, v. 19, n. 2}

\section{REFERÊNCIAS}

BARBOSA, A. M. Arte-educação: conflitos/acertos. São Paulo: Max Limonad, 1984.

BRASIL. Ministério da Educação: Parâmetros Curriculares Nacionais (Ensino Médio: Linguagens, Códigos e suas tecnologias). Brasília, 1999.

DELGADO, A. F. et. al. A reforma Curricular do Ensino Médio no Cepae sob a perspectiva dos alunos. Revista Solta a Voz, Goiânia, n. 2, p. 135-156, jul./dez. 2007.

JAPIASSU, R. O. V. Metodologia do ensino de teatro. Campinas: Papirus, 2001.

LUCK, H. Pedagogia interdisciplinar: fundamentos teórico-metodológicos. 3. ed. Petrópolis: Vozes, 1994.

PEREIRA, J. E. D.; ZEICHNER, K.M. A pesquisa na formação e no trabalho docente. Belo Horizonte: Autêntica, 2002.

SCHAFER, M. O ouvido pensante. São Paulo: UNESP, 1991.

Recebido em: 25 maio 2008 Aceito em: 29 set. 2008 